\title{
Saramago e Pepetela: As Representações dos Espaços em Memorial do Convento e A gloriosa família
}

\author{
Rosangela Manhas Mantolvani ${ }^{1}$
}

\begin{abstract}
RESUMO: Este trabalho trata de comparar a construção do espaço ficcional nas obras Memorial do Convento, de Saramago, e A gloriosa família: o tempo dos flamengos, de Pepetela; e considera que os espaços dos textos históricos são reconstruídos nas ficções com ênfase no espaço das margens.

ABSTRACT: This work aims to compare the construction of the fictional space in the novels Memorial of the Convent, by Saramago, and The glorious family: the time of the flamingos, by Pepetela, while considering the spaces of the historical texts reconstructed in fictions, by emphasizing the space of the margins.
\end{abstract}

PALAVRAS-CHAVE: Literatura comparada; ficção e história; espaços; ironia.

KEYWORDS: Comparative literature; fiction and history; spaces; irony.

$\mathrm{Na}$ arte e, assim, na literatura, o redimensionamento do espaço físico e social na obra de arte encontra-se sujeito ao posicionamento do criador no momento da seleção do material significante gerador de imagens, de tal maneira que este possa refletir uma outra realidade, que pode não distorcê-la, mas oferecer-lhe contornos especificamente ideológicos. Pois, segundo Bakhtin, "um signo não existe apenas como parte de uma realidade; ele também reflete e refrata uma outra. Ele pode distorcer essa realidade, ser-lhe fiel, ou apreendê-la de um ponto de vista específico". (BAKHTIN, 1981(b), p. 32)

Dessa perspectiva, o espaço na literatura aparece representado por um conjunto de signos específicos que nem sempre se referem a uma realidade extratextual, mas que é organizado de acordo com o posicionamento ideológico de seu criador, o qual seleciona os signos que irão representar um determinado espaço, o que permite a este transitar pelo metafórico e pelo alegórico, ainda que vinculando-o, ou não, a uma realidade exterior à produção artística.

$\mathrm{Na}$ ficção historiográfica, a ausência de um espaço extratextual concreto que the sirva como referência exige que essa reconstrução se encaminhe na direção de um

\footnotetext{
${ }^{1}$ Doutoranda em Estudos Comparados de Literaturas de Língua Portuguesa, FFLCH-USP. Pesquisa: Das invasões às fogueiras: os discursos ex-cêntricos em Pepetela e Saramago. E-mail: mantolvani@yahoo.com.br
} 
referencial exterior que é, também, textual (os documentos históricos, pesquisas antropológicas, histórias populares, lendas, etc.), onde podem se encontrar os registros das formas espaciais e sociais que possibilitem a construção de um espaço capaz de representar adequadamente a realidade ficcional possível de determinado período ou momento histórico.

O que permite a comparação entre Memorial do Convento (1982), de José Saramago e A gloriosa família: o tempo dos flamengos (1992), de Pepetela, no que diz respeito à construção do espaço ficcional é, entre outros pontos comuns, a forma pela qual os dois autores se apropriam dos espaços textuais e imprimem-lhes valores ideológicos que enfatizam o espaço das margens em detrimento dos espaços dos poder, por meio de um processo de paródia e ironia, transitando pelo viés do cômico-sério.

Tratamos, então, de revelar, por meio da comparação dos espaços recriados nas duas narrativas, como essas reinscrições constroem imagens que enfatizam a marcante divisão entre as camadas sociais, estabelecendo um profundo abismo entre os detentores do poder e a classe servil (os trabalhadores, os escravos), ou seja, as margens, desvelando a ideologia dos autores, Pepetela e Saramago, nessas criações.

A re(inscrição) do passado textual nesse tipo de ficção encontra-se, ainda, sujeita às releituras do ficcionista sobre a escrita do passado, de forma que as ideologias dos produtores daqueles séculos sejam confrontadas com outras forças ideológicas (as contraideologias) que, no mesmo espaço do texto da História, nas entrelinhas, se encontram silenciadas $^{2}$.

Sob esta perspectiva, a escrita ficcional da história oficial implica, então, em um processo de escrita que se constitui como paródia de um texto institucionalizado, enquanto a ficção entremeada nos construtos históricos trata de reescrever, com uma sobrecarga de ironia, aqueles espaços e fatos, tendo como resultado uma outra história.

A ficção constrói, então, por meio da escrita, uma contestação de certas formas de pensamento de época (aqui, especificamente, meados do século XVII e início do XVIII) que se encontram reafirmadas e, ali mesmo, contestadas, por meio da paródia, da ironia, produzindo o riso. Um riso, às vezes, macabro.

\footnotetext{
${ }^{2}$ Segundo Michel Pêcheux, no interior mesmo de um discurso dominante, é possível perceber nas entrelinhas, nos pressupostos e subentendidos, o discurso de uma outra formação discursiva que se encontra ali silenciada, que estabelece uma relação dialética com o texto em si.
} 
Assim, reescrever ou (re)inscrever, na literatura produzida no século XX, o espaço do século XVII, em Angola - A gloriosa família - e do XVIII, em Portugal - Memorial do Convento -, onde se movimentam os homens europeus, assim como outros grupos e povos as personagens da ficção -, significa reconhecer que é preciso delimitar as ideologias desses grupos, lembrando que as produções desses textos do passado se encontram sujeitas às ideologias dominantes de cada período histórico, assim como seus produtores.

O perfil ideológico dos homens desses séculos (especificamente no território angolano e em Portugal) encontra-se plasmado nas duas criações, cujo conjunto de idéias e práticas - seus modus vivendi - se acham representados nas construções narrativas que tratam de abordar, pelo viés do "cômico-sério" (BAKTHIN, 1988, p. 415;427) os aspectos sociais e econômicos em que viviam.

O espaço reconstruído nas narrativas corrobora, também, na representação dos homens e de seus lugares nas camadas sociais, pela oposição estabelecida entre esses espaços: o dos detentores do poder e o dos despossuídos. O contraste espacial reforça o poder das forças coercivas das classes dominantes, capazes de manter as massas populares fiéis à ideologia religiosa, fio condutor das mentalidades nos países ibéricos naquele período histórico: ${ }^{3}$

Há que observar, no entanto, que o confronto entre as formas de religião na Europa, a partir da Reforma Religiosa (iniciada no século XVI e estendida ao XVIII nos países ibéricos), que teve como conseqüência a reação do papado romano - a Contra-Reforma permitiu que o poder da Igreja de Roma, embora reduzido, utilizasse formas mais severas na submissão e controle do inconsciente das populações.

O confronto religioso que cindiu o cristianismo, separando os crentes entre católicos e reformistas, não se restringiu ao espaço europeu, antes se alastrou pelas colônias, cuja divisão marcaria, também, as disputas políticas e espaciais. É desse contexto que emergem as ficções abordadas neste trabalho e as tentativas de construção na literatura de espaços possíveis, redimensionados de acordo com os propósitos ideológicos dos autores.

\footnotetext{
${ }^{3}$ Para Marx, ideologia é um conjunto de idéias e conceitos que corresponde aos interesses de uma classe social, embora não obrigatoriamente professado por todos os seus membros. A ideologia decorre da posição que determinada classe ocupa num modo de produção historicamente determinado. Todo sistema de idéias se cria em relação estreita com circunstâncias históricas, econômicas ou sociais, numa interação dialética. Segundo ele, as condições da realidade determinam certo tipo de pensamento, e esse pensamento age sobre ela, modificando-a (ou não).
} 
A aplicação de sanções severas na seleção dos fiéis pela Igreja Católica, auxiliada pelo braço do Santo Ofício, cujos olhos encontravam-se voltados à certificação da fé católica em Portugal, estende-se às colônias portuguesas por meio das constantes tentativas de conversão dos então considerados "bárbaros" (os nativos) ${ }^{4}$ e dos infiéis (judeus, mouros e outros), cujas crenças não se adéquam às exigências da Igreja. Pode-se dizer que as perseguições, por vezes, não se encontravam exatamente relacionadas com a religião, pois havia, também, motivos escusos e sócio-políticos envolvidos. Segundo Harris:

o significado prático da bruxomania, portanto, foi que ela transferiu a responsabilidade pela crise agonizante da sociedade medieval da Igreja e do Estado para demônios imaginários que se apresentavam sob a forma humana. Preocupadas com as fantásticas atividades desses demônios, as perturbadas, alienadas, pauperizadas massas humanas culpavam o exuberante Demônio, em vez de culpar o clero corrupto e a nobreza rapace. (HARRIS, 1978, p. 176-177)

Dessa forma, a nobreza e o clero poderiam aparecer como os grandes protetores da humanidade, contra um inimigo onipresente que precisava ser descoberto, o que incitava as massas à delação. Envolvidas nessa mentalidade supersticiosa e nada científica, as personagens das narrativas de Pepetela e Saramago movimentar-se-ão nos espaços cujos vestígios e relíquias foram registrados pela História, cujas formas de pensar os incitava a construir seus produtos culturais e ideológicos.

Assim, os autores permitirão que as ideologias dominantes da nobreza e do papado de Roma funcionem como "pano de fundo" da construção textual, tonalizando os seus espaços. No entanto, uma outra ideologia será instalada como contestação dessa primeira, por meio de um discurso cuja valorização recai sobre o irreconhecido, sobre as vozes silenciadas pela ideologia da elite, e que não se encontram no texto, pois sofreram um processo de apagamento. Essas vozes são retomadas, através de um processo propiciado pela ironia e pelo paradoxo.

A voz narrativa encarrega-se de tonalizar a visão do espaço físico e social no romance, produzindo com viés cômico, irônico e sarcástico o espaço do poder, do luxo e do excesso, fazendo-o perverso desvendando-lhe as mazelas de sua existência e de sua reprodução, submetendo-o a processos do que Bakhtin considerou carnavalização da

\footnotetext{
${ }^{4}$ Ver ABDALA JR., B.; CARA, S. A. Moderno de nascença: figurações críticas do Brasil. São Paulo: 2006 (p. 9-10).
} 
literatura (Bakhtin, 1981 (b), p.105-106). E, pelo viés do sério, privilegia o espaço do precário, do trabalho, da miséria e da ausência de futilidades, tornando-o sublime.

$\mathrm{Na}$ Luanda do século XVI, um espaço de ocupação portuguesa, invadido por holandeses (1642-1648 em A gloriosa família), a presença de inúmeras igrejas justifica a necessidade daquele homem português movido pela ideologia religiosa: preservar seus templos. De acordo com Mircea Eliade "o templo constitui, por assim dizer, uma abertura para o alto e assegura a comunicação com os deuses" (Eliade, 1992, p. 29-30).

É também essa estrutura urbana com inumeráveis templos que marca o cenário espacial e o percurso da rainha, D. Maria Ana, em Memorial do Convento, onde, além de inúmeras igrejas, encontram-se conventos e mosteiros abrigando populações de homens e mulheres enclausurados em nome da fé.

Ocorre que nas representações dos locais - considerados, então, sagrados pelos textos históricos de suas épocas - ambos autores os reconstroem ficcionalmente, agora, deslocando e imiscuindo, entre as características do sagrado, os elementos do considerado mundano e profano por aquelas mesmas sociedades, desvelando a relatividade das afirmações do passado textual, sugerindo um material descartado pela História como factual.

Assim, Pepetela faz questão de enfatizar a divisão do cristianismo na Luanda do século XVII com a chegada dos chamados "hereges" calvinistas, fiéis à doutrina da reforma religiosa, que, à exceção de uns e outros, transformam o colar de igrejas que contornam a cidade colonial em circuito de privadas, depósitos de lixo e locais propícios a atos considerados impudicos pelos que se dizem católicos.

Nesse grupo, encontra-se a personagem Matilde Van Dun que comete adultério em plena sacristia da Igreja do Corpo Santo, com o tenente Joost Van Koin, e, também, a personagem do Padre Tavares, que intenta seduzir o jovem Hermenegildo, declarando suas intenções homossexuais na Igreja de N. Sra. da Conceição. Nessas construções literárias encontra-se a categoria da profanação, uma das quatro do que Bakhtin definiu como carnavalização da literatura. Memorial do Convento, por focalizar Lisboa e a própria construção de uma obra da arquitetura contra-reformista do século XVIII - dado o atraso científico de Portugal - tem sua construção literária permeada pelas Igrejas, Mosteiros e Conventos como imagens recorrentes, enquanto o deslocamento do sagrado e a instalação do sacrilégio nesses espaços retomam a categoria da profanação. 
Tanto Pepetela quanto Saramago tecem ácida crítica ao silenciamento da história sobre os atos sacrílegos praticados pela nobreza e pelo clero, sob os auspícios do Santo Ofício, e passíveis de denúncia. Entre esses, o envolvimento do rei D. João V com Madre Paula (Paula Teresa da Silva), cujos encontros se davam nas celas do convento de Odivelas. E contra a prática de certos religiosos, representada pela cena em que Blimunda procura ajuda no mosteiro próximo a Mafra e sofre tentativa de violação por parte do frade dissimulado que a convida a pernoitar. Estas, apenas algumas, entre as inúmeras denúncias.

Em ambas narrativas, a presença dos templos católicos é uma constante, de modo que a cidade colonial estabeleça com a metrópole uma relação especular, onde um microcosmo trata de refletir o macrocosmo, bem como a reprodução de seus valores ideológicos. Assim, alguns nomes de igrejas são inclusive coincidentes, como a da Sé, por exemplo, presente em Luanda e também em Lisboa, e, na Colônia, a Igreja de Nossa Senhora da Conceição, a Igreja de Jesus, a Igreja do Corpo Santo, entre outras. Numa pequena cidade colonial como Luanda, a presença de tantos templos indica o domínio ideológico do catolicismo de Roma.

Assim, essas ficções tratam de afirmar a religião como ideologia e, por meio da reescrita do interdito, do silenciado, estabelecer o paradoxo por meio da ironia e do contraste. No espaço do sagrado se desvela o que há de profano e, no espaço do então considerado mundano, consolidam-se os sentimentos sublimes no universo das relações humanas, estes, deslocados para o espaço exterior das grandes instituições, à margem dos espaços do poder.

É no espaço do "provisório" que acontecem as cenas do amor eterno entre o casal Blimunda e Baltasar - Memorial do Convento -, cujo primeiro contato, mais intuitivo que físico, ocorre no largo do Rossio e sua primeira noite de amor na casa de Blimunda, um apêndice exterior, simples e pobre, construído à margem do castelo (uma das paredes da moradia era o muro do castelo). Os momentos de intimidade acontecem em ambientes muito simples, como na abegoaria da Quinta do Duque de Aveiro, nas barracas do acampamento em Mafra, ou, ainda, no assoalho de madeira da Passarola, construídos pelo viés do sério, encontram-se sobrecarregados de subjetividade e simbologia em que se venera toda a força das necessidades humanas.

Em Pepetela, o mesmo ocorre com os momentos de amor, como no relacionamento de Thor, o escravo da Lunda, com Rosário, cultivado entre as flores do jardim, no espaço 
do quintal e concretizado atrás das paredes das humildes cubatas, n' A gloriosa família. No espaço marginal, o humano, o mundano, é que congrega o sagrado.

Ao tratar os locais exteriores ao centro, afastados do poder, pelo viés do sério, os narradores assumem uma posição comprometida com o espaço das margens, com o espaço dos excluídos da história dos dominantes, silenciados no tempo e no espaço pelas instituições absolutistas, afrontando o pensamento monológico e valorizando, na ficção, o mundo do trabalho e o homem comum como construtor de sua própria história.

A literatura de Pepetela não se esgota nas disputas religiosas entre calvinistas e católicos, mas contempla as religiões locais, tratando da questão dos kimbandas que, por ocasião da invasão dos protestantes continuam proibidos de adentrar pelas cidades e, se antes eram queimados nas fogueiras pelos católicos, agora são banidos, declarados usuários das artes do demônio pelos calvinistas, enquanto buscam esconderijos nos kimbos ${ }^{5}$, onde são protegidos pelos sobas, a exemplo de Sukeko, um curandeiro que domina a fitoterapia.

O contraponto ao fitoterapeuta da tradição angolana, em Memorial do Convento, é a personagem do padre Bartolomeu Lourenço, o Voador, cientista e inventor, que obtém em Portugal pequeno apoio de D. João V para seu projeto, escondido, também, em uma pequena oficina na Quinta do Duque de Aveiro, um espaço marginal, onde constrói sua engenhoca voadora, cuja inovação tecnológica é ameaçada pelos ditames da "heresia".

Se em A gloriosa família a ciência nativa local sofre perseguição por parte dos calvinistas e católicos, que preferem ver nos efeitos curativos das ervas as artes do demônio, em Memorial do Convento é a ciência da tecnologia de época que se sente ameaçada como arte do demônio. Cada qual em suas singularidades, os autores oferecem às reflexões do presente as diferentes perspectivas que se pode adotar diante da ciência. Por outro lado, retratam a opressão de um passado fadado ao martírio e às penitências terrenas.

Em Memorial do Convento, o espaço de Mafra é reverenciado pela Igreja, a qual compara seus trabalhadores a penitentes, mas é ironizado pelo narrador, enquanto o viés do sério é adotado para construir o espaço da abegoaria, cuja desapropriação funciona como metáfora crítica da desvalorização da ciência: uma alegoria à perseguição que a Igreja desencadeou a muitos cientistas, escritores e artistas da época. É a crítica de Saramago, que encontra sua reflexividade na contemporaneidade.

${ }^{5}$ Cidade tradicional africana 
O espaço do poder, como o Palácio do Rei, em Lisboa, é sempre o alvo preferido da ironia do narrador, tendo em vista o hobby de D. João V - montar e desmontar a maquete da basílica de São Pedro, que se transforma em brinquedo dos príncipes -, ou os inúmeros protocolos do cerimonial: supérfluos, repetitivos, assistidos por incontáveis funcionários ociosos, quando do ato sexual entre a rainha e o rei, ou da imobilidade da rainha, após o ato sexual, ou as referências à cama do casal, vinda de Holanda, e empestada de percevejos, onde a rainha dormia sozinha, envolta em seus suores excessivos.

O mesmo processo de paródia e caricaturização de personalidades históricas é reiterado em Pepetela, também nos espaços do poder, seja no Palácio dos Governadores, pela cômica figura do diretor da Companhia das Índias Ocidentais, Redinckove, autoridade máxima em Luanda, cujo comportamento é ironizado freqüentemente, ou a personagem do Major Gerrit Tack que aceita compartilhar a prostituta francesa com o diretor, inaugurando um couple de trois: comportamentos avessos às pregações dos predikants.

No espaço do poder, os governadores portugueses não escapam à ironia do narrador, que não se cansa de denunciar os desvios de caráter de Pedro César de Meneses: a ambição, o medo e outras covardias. O próprio patriarca da família Van Dun constrói-se como medroso já no início da narrativa, quando urina nas calças ao ser chamado pelos holandeses para explicar certas relações com os portugueses, sem contar os gases que poluem o ambiente toda vez que se irrita.

Assim, o que escapa às críticas dos narradores e, muitas vezes, é enaltecido, encontra-se à margem do poder, e, também, à margem da historiografia oficial: os esfomeados e rotos trabalhadores de Mafra e suas famílias, os condenados da Inquisição, os cientistas e artistas em Memorial do Convento. N'A gloriosa família, são as populações locais, a figura de Jinga e dos kimbandas, as chefias jagas, Thor, o escravo da Lunda, os escravos trabalhadores, os judeus e alguns filhos de Van Dun os focos das representações que não sofrem o crivo da ironia e da caricaturização.

Nas ficções de Pepetela e Saramago, os espaços do poder são submetidos a profundos abalos morais. O espaço do poder privilegiado pela História oficial é contestado pelos narradores, enquanto o espaço ocupado pelos grupos marginais e suas vozes são privilegiados, produzindo relações antitéticas, e revelando a relatividade de algumas historiografias oficiais do passado, bem como seus vínculos ideológicos com o poder central das épocas. 


\section{Referências bibliográficas}

BAKHTIN, Mikhail. Problemas da poética de Dostoiévski. trad. Paulo Bezerra. Rio de Janeiro: Forense- Universitária, 1981 (a).

BAKHTIN, Mikhail. Marxismo e Filosofia da Linguagem. 2.ed. Trad. M. Lahud; Y. Vieira. São Paulo: Hucitec, 1981(b).

BAKHTIN, Mikhail. Questões de Literatura e Estética. A teoria do romance. Trad. A.F. Bernardini; J. Pereira Jr.; A. Góes Jr.; H.S. Nazário; H. F. Andrade. São Paulo: Ed. Unesp/Hucitec, 1988.

ELIADE, Mircea. O sagrado e o profano: a essência das religiões. trad. Rogério Fernandes. São Paulo: Martins Fontes, 1992.

HARRIS, Marwin. Vacas, Porcos, Guerras e Bruxas: os enigmas da Cultura. Rio de Janeiro: Civilização Brasileira, 1978.

PEPETELA. A gloriosa família: o tempo dos flamengos. Rio de Janeiro: Nova Fronteira, 1999.

SARAMAGO, José. Memorial do Convento. 26. ed. Rio de Janeiro: Bertrand Brasil, 2001. 